technology, incomprehensibility may not matter. But to the theoretical psychologist it is a challenge that has already led to the introduction of new methods of data analysis, and one may look forward to an exciting moment when top-down and bottom-up approaches to the musical mind finally meet in the middle.

Christopher Longuet-Higgins is at the Centre for Research in Perception \& Cognition, University of Sussex, Falmer, Brighton BN1 9QY, UK.

\section{The world as a patchwork}

\section{Metapopulation Ecology}

by Ilkka Hanski

Oxford University Press: 1999. 313 pp.

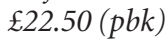

\section{Camille Parmesan}

As we field biologists see our favourite study sites succumb to anthropogenic assaults, we must increasingly spend our time searching for 'pristine' habitats in which to study natural ecological phenomena. They are nearly impossible to find, but, if found, are cherished for whatever information can be gleaned before they, too, become victims of the plough or the axe, acid rain or nitrogen run-off. Of necessity, ecologists have either partially or wholly redirected their research towards the effects of these and other anthropogenic disturbances on remaining 'natural' systems.

This shift has not come easily to those trained in classical ecology - the purist's sentiment that basic research is superior to these more 'applied' questions is alive in all ecological sub-disciplines. Fortunately, many researchers (at all levels) now regard such classical idealism as snobbery at best, and harmfully delusional at worst. Ilkka Hanski shows his colours by stressing practical applications throughout this tour de force exposition of the metapopulation approach to ecology, evolution and conservation biology.

The metapopulation approach recognizes the influence that otherwise discrete populations can have on one another when neighbouring patches exchange small numbers of migrants. This network of populations, when viewed in its own right, may express very different dynamics from those of its separate population components.

The accelerating growth of this field, fuelled in large part by Hanski himself, has ecologists in other areas looking nervously askance. How much bigger can this bouncing babybecome? Will it come to define conservation biology? Can the world be finally understood only if we consent to view it through an Esheresque maze of ephemeral patches set within networks of even more patches?

Fear not. Here lies neither a diatribe nor a plea. Hanski meticulously details the history, growth and empirical and theoretical underpinnings of metapopulation biology. $\mathrm{He}$ approaches the subject in a down-to-earth manner, concentrating on his prime motivation - to present a variety of concepts and models which may help us to understand and conserve what still remains. Being equally astute in theory and empiricism, he manages this with aplomb.

While admitting that the metapopulation approach will not apply in every instance, Hanski attacks its sceptics in a lively manner: "I want to make the point that ignoring the actual spatial population structure of any species, at whatever the scale that structure might occur, would be an exceedingly silly thing to do." Bravo! Leave the philosophically inclined to debate the delineation of a population, and let's get on with the business at hand.

And serious business it is - this book is not for the faint-hearted. The density of information, page after page, is rather like a Yorkshireman's description of a good cup of tea - thick enough to stand a spoon in. Hanski's attempt at making his work accessible to the bulk of population biologists is generally successful, and impressively eloquent in arguments he considers crucial. However, he also assumes a high degree of knowledge, as well as motivation to understand the subject. I would suggest new graduate students have a basic ecology text or dictionary handy to follow the arguments fully. The casual reader can still come away somewhat enlightened, as plainly written summaries begin and end each chapter, and often each section. Frankly, I found his treatment a refreshing refusal to cater to the lowest common denominator.

Unfortunately, Hanski's impressive style is ill-supported by abysmal print quality. The blurred outlines of the letters complemented the small, overly-serifed font to give me a solid headache within 20 minutes of reading. I thought I needed glasses, when in fact I needed a different production editor.

I applaud Hanski for embracing what many ecologists emotionally reject: the incorporation of evolution into what has largely been an ecological domain. Indeed, the few empirical genetic studies that do exist bolster his assertion that "local adaptation influences spatial dynamics and spatial dynamics influence local dynamics". However, evolutionists must be prepared for an unconventional use of "fitness" to refer to population growth rate (as well as to individual fitness) - a usage justified by model results which show that population growth rate can be important to evolution at the metapopulation scale.

I learned a lot in areas I knew dimly and was entertained in areas I knew well - a sure sign of a good book. Hanski's emphasis on the application of models, particularly to conservation biology, will make this work not only a classic for academic population biologists, but an essential reference for managers and conservation planners as well.

Camille Parmesan is at Integrative Biology, Patterson Laboratories, University of Texas, Austin, Texas 78712, USA.

\section{Taking a gender tiger by the tail \\ Why So Slow? The Advancement of Women \\ by Virginia Valian \\ MIT Press: 1999.424 pp. $\$ 17.50, £ 12.50$ (pbk) \\ Christine Wennerås and Agnes Wold}

Despite the large influx of women to universities during the past three decades, women's academic careers are generally far less brilliant than those of their male peers. Common prejudice tells us that this is largely due to 'women's special priorities', for example that women nurture their families rather than their careers. In fact, married women with children are at least as scientifically productive as single women, and advance equally, or more, rapidly than their childless female colleagues. Further, no simple relation between the role of women in society at large and their capacity to climb the academic career ladder can be found. For example, the 'women friendly' Scandinavian countries have excellent child care and a high proportion of women politicians, but a glaring scarcity of female professors.

The reasons for the slow advancement of women in the academic system must be sought within the system itself. Resources necessary for doing research - positions, laboratory space, personnel and money are limited, and their distribution is as a rule based on the judgement of peer reviewers. In both Sweden and Denmark, a gender-specific difference in the success rate of attainment of postdoctoral positions and research grants has been documented, to the detriment of women. Recently, the Massachusetts Institute of Technology admitted to having given fewer resources to female than male scientists of equal seniority (see http://web.mit.edu/fnl/women/women).

In Why So Slow? The Advancement of Women, Virginia Valian has compiled studies on the slow progress of women in professional life, its possible causes and potential remedies. Her theory is that a continuous accumulation of small advantages for men and small disadvantages for women operate insidiously, resulting in very different career opportunities for the sexes. A multitude of cited studies demonstrate that evaluators as a rule overestimate the performance of men and underestimate that of women.

Valian didactically explains the roots of prejudice and stereotyping. The simple belief that two groups of people are different 
will taint the evaluation of an individual from either group, impeding a clear-headed evaluation of that person's merits. Stereotyping is a basic human inclination, which probably evolved, according to Valian, to facilitate speedy judgement - if one sees a tiger, it is better to have prejudiced ideas on the aggressiveness of that tiger, based on previous encounters with other tigers or hearsay, than to wait and see how this particular tiger behaves. Girls and boys, men and women, are perceived and treated differently even in cases where the two sexes behave in exactly the same way. Valian calls this stereotyping "gender schemata", and shows that women as well as men firmly believe in psychological differences between the sexes, when, in fact, no psychological tests have shown any such differences.

Valian's reasoning is straightforward and easy to follow, with one exception. Although she begins by rightly pointing out that women and men are alike in all measurable psychological variables, she contradicts herself by referring to studies where women are shown to be more 'feminine' than men, who instead more often are 'masculine'. What kind of traits does Valian allude to? The 'masculinity-femininity scale' was constructed by American psychologists based on people's opinions of what constituted typically feminine and masculine traits. Based on which traits men and women picked from these lists to describe themselves, they were defined as being masculine or feminine. Here, academic psychology has achieved a perfect circular reasoning in order to preserve outdated gender stereotypes. This is not Valian's fault - but the book would have done better without it.

Valian argues that women and men are equally biased against female performance. This is indeed true of experimental psychology studies performed in the 1970s and early 1980 s, but some more recent studies indicate that women are adopting a more genderneutral evaluation behaviour while men continue to underestimate female achievement. Most likely, in the past 20 years, women have become aware of gender inequalities in society and have tried to correct their behaviour. This point is of some importance, because if women are less biased against female achievement than are men, there is urgent reason to increase the number of women evaluators.

This book should be read by anyone interested in the field of gender equality, but, more importantly, by those who are not interested in such issues. The ideal target group should be people in power who live under the illusion that they 'always treat men and women alike?.

Christine Wennerås is in the Department of Medical Microbiology and Immunology, and Agnes Wold is in the Department of Clinical Immunology, Göteborg University, Guldhedsgatan 10, SE-413 46 Göteborg, Sweden.

\section{Science in culture}

\section{Hay-on-Wye Festival of Literature and the Arts}

(28 May-6 June 1999)

John Maddox

D $\mathrm{epo}$ eports to the contrary notwithstanding, popular enthusiasm for science is alive, well and brimming over in this improbable setting. Hay-on-Wye is an old Welsh border town (where the border is that with England, now pushed further east under new parliamentary arrangements). The town was revived and put on the map in the 1960s by one Richard Booth, whose entrepreneurship has given it a large network of second-hand bookshops. Quite independently, the town has been for the past decade the site of a bucolic literary festival, held in huge tents scattered around the elementary school, with views of rolling fields and hills rendered intense green by the heavy and persistent rain familiar in these parts.

Science has by accident infiltrated the standard programme of a literary festival. If it makes sense to celebrate the latest Doris Lessing or Edna O'Brien book by asking the authors to come and talk, why omit Stephen J. Gould, Stephen Hawking and Stephen Pinker? (This festival also embraces politics - witness the regular visits by the handful of literate British parliamentarians and by luminaries such as F. W. de Klerk, quondam president of South Africa.)

This year's science offerings outdid all previous years, which is partly a measure of the increased volume of popular-science books on the market and partly a deliberate decision by the organizers to give the audience more of what it seems to clamour for. This year, the geneticist Steve Jones (from University College London) almost filled the 1,000 seats in the largest of the tents with a talk on the question of whether human evolution has now come to a halt. But there were a dozen other science talks spanning cosmology (by Paul Davies from Adelaide, John Gribbin - an old Nature hand - and Chandra Wickramasinghe, the iconoclast from Cardiff) and the question of where and what is mind (by Bristol psychologist Richard

Gregory, journalist Rita

Carter, neurologist

Christopher Frith and

Ian M. Glynn, the now retired professor of physiology at Cambridge).

Studied

informality is the order of the day for presenters. Steve Jones, a regular visitor, this year abandoned his customary sweater and slacks for a dark doublebreasted suit and gleaming white shirt (but no tie), but

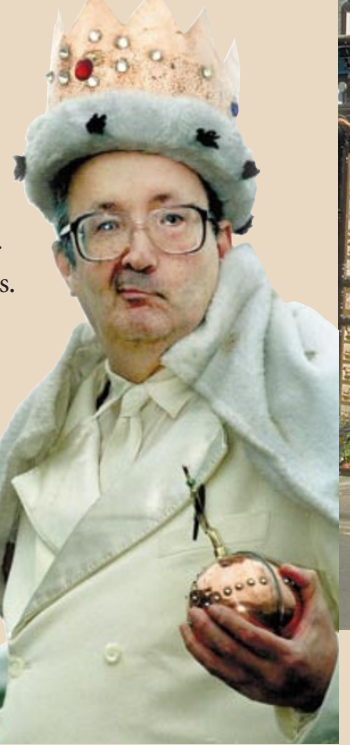

that was only illusion: in no time at all, the jacket was thrown over the back of a chair and Jones was back in his element. When the rain thundered on the roof of the tent, Jones was able to send the audience into gales of laughter simply by turning his eyes towards the heavens.

Questions at Hay are thoughtful and intelligent, if usually prefaced by "I am no scientist". Mercifully, the audience seems to have given up asking every speaker whether he or she believes in God (maybe the answers were too uniform). But this year Jones ducked the question of whether, if evolution "by means of natural selection" had now halted, people might themselves take a hand in the process by genetic manipulation. These occasions need a chairman.

Meanwhile, why are huge crowds flocking to science talks at Hay? Much of the audience seems to consist of schoolteachers occupying the weeklong break that British schools enjoy at the end of May. The festival director, Peter Florence, says that those who come to Hay are hungry for learning of all kinds, not just for refresher courses in their own fields. Whatever the explanation, on this year's showing, it is an occasion at which authors whose books have been ignored by reviewers in the fashionable press can be sure of an appreciative audience and can even be flattered by the chance to sign books in a crowded tent with rain hammering on the roof.

John Maddox is at 9 Pitt Street, London W8 4NY, UK.

- Next year's festival runs from 27 May to 4 June.

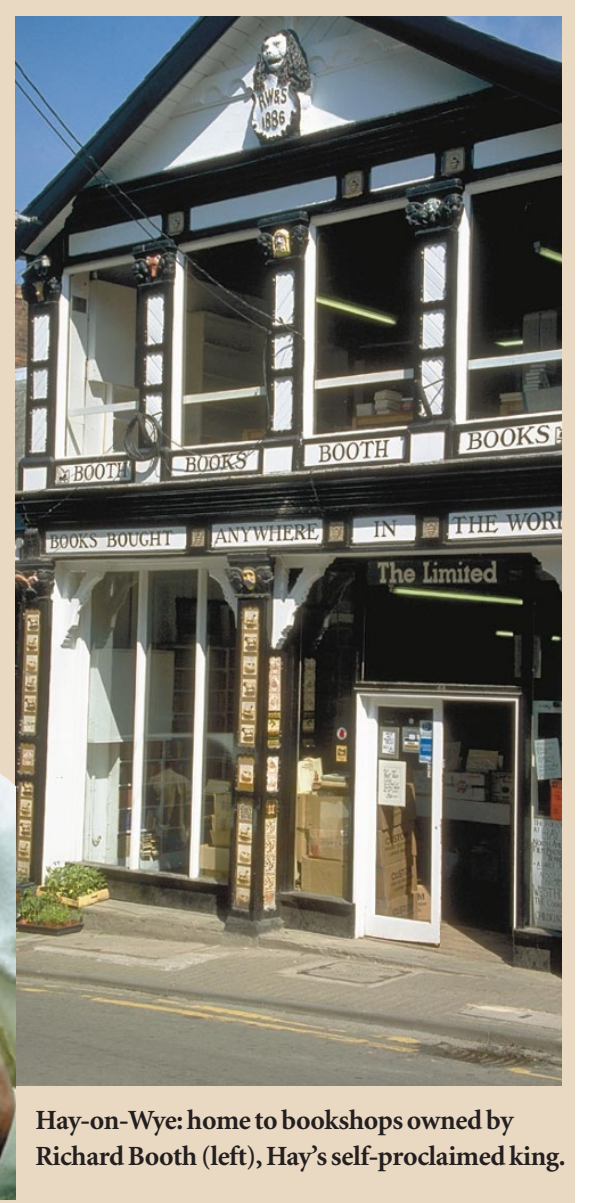

